\title{
How to make chips to order
}

\section{Menlo Park, California}

THE Stanford Research Institute (SRI) International, the commercial contract research institute, claims to have carried the technology of electron beam lithography to the point at which the technique can be used for making individual semiconductor microchips, not simply the masks used in semiconductor mass production. Those responsible say that the technique has hitherto been too slow to be used in mass production, where optical lithography remains the chief technique. But SRI will need a commercial partner - and millions of dollars - to commercialize its machine.

According to Dr Ivor Brodie, director of SRI's physical electronics laboratory, the growing demand for bespoke microchips, both in silicon and gallium arsenide, has helped to make electron beam lithography a commercial proposition. SRI is now looking forward to a market that could be worth $\$ 1,000$ million a year by 1992 . Brodie says that the demand for bespoke chips was not foreseen. "People want a particular integrated circuit for a particular purpose, and do not want others to copy it", he says. Instead of relying on general-purpose devices programmed for particular functions, he says, "people are now doing the programs, as it were, by hard-wiring".

The SRI machine is certainly quick. A semiconductor wafer $200 \mathrm{~mm}$ in diameter, and typically carrying 1,200 separate chips, can be "written in about a minute", according to Brodie, who says that with existing electron beam machines, it takes between half an hour and an hour to "write" a mask of the same size.

The electron beams in the SRI design are fired from an electron gun, focused through a screen of lenses at zero volts to the wafer being processed, which is itself maintained at a higher voltage. The multiple beams can be switched off and on by adjusting the voltage. By the use of several beams, it is possible to etch an identical pattern on several different parts of a semiconductor wafer, thus allowing several identical integrated circuits to be created simultaneously.

NASA Lewis Research Center and the Naval Research Laboratories have led SRI to develop custom-made microchips that could miniaturize CRTs. Capp Spindt. senior research engineer leading the project, says that NASA's interest was originally inspired by the need for a source of high current density for its satellite communications. Thermionic emission on cathodes were inefficient, needing heat to excite electrons from an element into the vacuum to create the electron beam. SRI's approach is based on field emission techniques in which electrons are produced by tunnelling to the surface of the metal on which is induced a high electric field. The process is efficient.

Using this foundation, SRI has developed microchips which produce veryhigh-current densities - more than $60 \mathrm{~A}$ $\mathrm{cm}^{-2}$ to $100 \mathrm{~A} \mathrm{~cm}^{-2}$ or about three times the current densities normally expected of thermionic emission. The design, says Spindt, is based on the well-tried methods adopted for years in the semiconductor industry - a sandwich of metal, silicon oxide and silicon (MOS).

Using electron beam lithography, the researchers were able to etch out the de ign creating a pattern of holes in the substrate into which they could insert a metal, the source of electron emission. "You have this metal film with a hole in it. You have an insulator spacing it ... and the ground plane silicon you can work from. And it's very closely spaced. Then we developed a technique for growing a very sharp point which rests on the silicon."

The distances between these holes are about $2 \mu \mathrm{m}$, giving densities of more than $1.2 \times 10^{6}$ tips per $\mathrm{cm}^{2}$, and arrays with more than 10,000 tips have been fabricated. Very high current densities result when the device is electrically excited. The next stage in the development is to explore how the technique can be used to enhance the designs of displays. The high current densities are expected to make any CRT picture brighter - and therefore ideal where the environmental light is at a high level, as in a cockpit/flight-deck and because of the compactness of the silicon, to reduce substantially the width of any display.

\section{Creationism}

\section{California sells out on textbooks}

\section{Washington}

Evolutionists in California were bitter last week about what they call a "sham" hearing held by the State Board of Education that approved revised biology textbooks for state schools despite "hundreds" of factual errors and weak coverage of evolution. Revisions made by the publishers to take account of criticisms by the state's curriculum commission introduced more errors than they eliminated, according to William Bennetta, who has been working for better treatment of evolution in textbooks.

The revisions were made after the curriculum commission recommended in September that the books, for twelve- and thirteen-year-olds, should not be accepted because of their avoidance of evolution and inadequate treatment of human reproduction and ethical questions Publishers are anxious not to offend the strong US creationist lobby, which has threatened to sue in California over the

\section{Aleksandrov's fate?}

Almost nine months after the disappearance of Soviet computer scientist Vladimir Aleksandrov in Spain, the Soviet Academy of Sciences last week said that he had disappeared without trace in Madrid on 1 April on his way home from an international conference of mayors of "nuclearfree" towns. Diplomatic representations had received "no clear reply". The academy did not explain why it had been officially silent for so long. But Soviet unwillingness to discuss the disappearance has, undoubtedly, fuelled rumours circulating in the West that Aleksandrov, coauthor of the Soviet nuclear winter computer model, had been intending to defect, but was prevented by Soviet security men. Vera Rich books now approved. California represents more than 10 per cent of the US textbook market.

A spokesman for the state board said that the books had been greatly improved by the revisions. Publishers had threatened that a failure to adopt the revised books last week would have made it impossible for books to be produced in time for the start of the academic year next September; because textbooks are adopted in California on a six-year cycle, a delay could have held up planned improvements to books in other subjects. $\mathrm{Dr}$ Bill Honig, state superintendent for public instruction, said he believed the books now to be the best in the country. A final review by a curriculum commission subcommittee would be able to eliminate any factual errors in the books that were identified at the hearing.

Bennetta and his supporters are not impressed with this promise, pointing out that the subcommittee has no biologist among its members. Most of the books were not altered extensively, as the evolutionists thought necessary, and even those that made significant changes avoided open acknowledgement that evolution is the received wisdom, often using such terms as "many scientists feel" as qualifiers.

The evolutionists complain that the revised books were deliberately made difficult to examine (one copy only was exhibited, for 12 working days, in the state capital) in order to minimize the risk that errors and weaknesses would be exposed. Bennetta's favourite example is in Health Life Science, published by Heath and Company, where a statement in the original version that "many scientists believe that dinosaurs were the ancestors of reptiles" has been replaced with the assertion that scientists classify dinosaurs as the ancestors of reptiles. 